\title{
SOCIEDADE DE CONSUMO, GLOBALIZAÇÃO E PRECARIZAÇÃO DAS RELAÇÕES LABORAIS NA TERCEIRIZAÇÃO.
}

\section{SOCIETY OF CONSUMPTION, GLOBALIZATION AND PRECARIZATION OF LABOR RELATIONS IN THE OUTSOURCING.}

\author{
Emerson Victor Hugo Costa de Sá1
}

\section{RESUMO}

No mundo globalizado, as demandas da sociedade de consumo influenciam as condições de trabalho. Caminhou-se pelo taylorismo, fordismo e toyotismo, para expor a vinculação da realidade trabalhista à flexibilidade produtiva. Tratou-se da precarização do labor, por meio do exame das peculiaridades da terceirização, especialmente quanto aos direitos fundamentais e ao meio ambiente do trabalho. Finalmente, examinou-se a viabilidade jurídica da subcontratação de atividades finalísticas dos empreendimentos, cuja liberação constitui objeto de proposta legislativa que pretende regulamentar o instituto da terceirização no país. Utilizou-se como metodologia a pesquisa bibliográfica e documental, tendo como parâmetros livros, artigos científicos e textos normativos.

Palavras-chave: Globalização; Capitalismo; Terceirização; Atividade-Fim; Precarização.

\begin{abstract}
In the globalized world, the demands of the consumer society influence working conditions. Taylorism, Fordism and Toyotism show the linkage of labor reality to productive flexibility. The precariousness of labor was exposed through the examination of the peculiarities of outsourcing, especially regarding fundamental rights and the environment of work. Finally, the legal feasibility of the subcontracting of the final activities of the enterprises was examined, whose release is object of a legislative proposal that intends to regulate the outsourcing institute in Brazil. Bibliographical and documentary research was used as methodology, having as parameters books, scientific articles and normative texts.
\end{abstract}

Keywords: Globalization; Capitalism; Outsourcing; Activity-End; Precariousness.

\footnotetext{
${ }^{1}$ Auditor Fiscal do Trabalho. Mestrando em Direito Ambiental na Universidade do Estado do Amazonas - UEA, Amazonas, (Brasil). Graduado em Direito (Universidade Federal do Amazonas).

E-mail: emersonvictor.sa@gmail.com
} 


\section{INTRODUÇÃO}

A globalização provoca efeitos colaterais inegáveis. As demandas da sociedade de consumo geram a necessidade de mudança nos modelos produtivos. No mundo capitalista, essas alterações refletem diretamente no cotidiano das pessoas que vivem do trabalho. $\mathrm{O}$ caminho trilhado pela economia tem prejudicado o aparato protetivo laboral, ignorando as lutas travadas pelas organizações obreiras em busca de melhores condições de trabalho.

O desenvolvimento da pesquisa compreende, inicialmente, a apresentação de três dos principais sistemas produtivos. Parte-se do taylorismo, passa-se pelo fordismo e centra-se a análise no toyotismo, atualmente dominante e responsável por grande parte da angústia vivenciada no mundo do trabalho. Nesse momento, são expostos alguns dos reflexos negativos vinculados à ideia de flexibilidade produtiva propugnada pelo modelo.

Em seguida, trata-se especificamente da precarização das relações de trabalho, com foco nas características e peculiaridades do instituto da terceirização, especialmente no que tange às agressões dirigidas aos direitos fundamentais do trabalho e ao meio ambiente laboral.

Por último, são tecidas considerações a respeito do Projeto de Lei da Câmara (PLC) 30/2015 - anterior PL 4.330/2004 -, que pretende regulamentar o instituto da terceirização no Brasil. O principal ponto de discussão consiste na pretensão de o projeto autorizar a prática da terceirização em hipóteses atualmente vedadas pela Súmula 331 do Tribunal Superior do Trabalho (TST), parâmetro jurisprudencial que serve de referência sobre o tema. Analisa-se a viabilidade jurídica da liberação de subcontratações nas atividades finalísticas dos empreendimentos. Para tanto, examina-se o conjunto normativo protetor do regime de emprego, que preza pela prevalência da vinculação direta do trabalhador ao tomador dos serviços e preconiza a função social da livre iniciativa.

O estudo das consequências da proposta no cotidiano dos trabalhadores mostra-se imprescindível. Questiona-se: Quais os impactos da terceirização no mundo do trabalho? Que prejuízos sofrem os terceirizados frente aos empregados diretos? É viável liberar a terceirização nas atividades finalísticas, além das já admitidas acessórias e específicas?

A abordagem metodológica desenvolveu-se a partir de pesquisa bibliográfica e documental, tendo como parâmetros livros, artigos científicos e textos normativos. 


\section{DO TAYLORISMO AO TOYOTISMO}

A expansão do sistema capitalista pelo mundo consolidou a integração dos mercados, promoveu a modificação das estruturas econômicas e influenciou o comércio, a cultura e os modos de produção. As revoluções industriais - sobretudo a tecnológica - incentivaram a globalização e a implantação de diferentes políticas produtivas, como o taylorismo, o fordismo e o toyotismo.

O desenvolvimento de novas técnicas produtivas tem por fim viabilizar melhores resultados, mediante a redução dos custos e a maximização dos lucros. Essas medidas refletem diretamente nas relações laborais. O capitalismo prioriza os objetivos de lucro dos detentores dos meios de produção em detrimento dos anseios do proletariado por melhores condições de trabalho e remuneração. Essa contraposição de interesses resolve-se desfavoravelmente ao lado mais frágil.

Fundada no direito de propriedade, a ideologia liberalista promove transformações sociais ao reestruturar continuamente os modos de produção e as relações laborais. A concepção taylorista instituiu a organização científica do trabalho, amparada na separação entre as etapas de idealização e de execução, e no parcelamento das atividades, para reduzir o tempo de produção. Por sua vez, o fordismo pautou a produção na linha de montagem, para responder ao aumento da demanda e permitir a produção em massa, propugnando a estrutura verticalizada e o total controle sobre o processo. A partir do terceiro quarto do século passado, a expansão do neoliberalismo exigiu a superação do fordismo, foçando a alteração do padrão produtivo. Surgiu, então, o toyotismo, filosofia que ocasionou novas mudanças nos processos de trabalho e persiste dominante até os dias atuais.

Com o toyotismo, ganham força conceitos como o de produção enxuta (proporcional à demanda e ao crescimento), vinculada à ideia de estoque mínimo, para atender às exigências específicas do mercado no menor tempo e com maior qualidade. Flexibiliza-se a organização e, ao mesmo tempo, a exploração do trabalho, ao serem intensificadas as exigências de multifuncionalidade e maior qualificação obreira. Altera-se a concepção vertical para a horizontal, com a redução dos níveis de hierarquia e a distribuição das atividades específicas e periféricas para outros núcleos produtivos, tendo em vista a melhoria do produto e do tempo de resposta aos pedidos do mercado.

As relações de trabalho seguem o mesmo raciocínio de flexibilização aplicado ao aparato produtivo, vez que a exploração da força laboral depende da demanda proveniente da sociedade de consumo. Quando o mercado está em alta, exigem-se horas extraordinárias, intensifica-se o ritmo produtivo ou contratam-se mais trabalhadores temporários. Por outro lado, quando há decréscimo na demanda, os quadros são reduzidos e o desemprego agrava-se. Essa instabilidade reduz o patamar protetivo laboral e provoca a exclusão social do trabalhador, privando-o da segurança no emprego.

Marca desse novo modelo produtivo, a terceirização - contratação de uma empresa (prestadora), que fornece a força de trabalho (terceirizado) para a execução de um serviço junto à contratante (tomadora) - responde por grande parte da precarização. A título de exemplo, o terceirizado experimenta a redução da média remuneratória, comparativamente ao que perceberia se fosse diretamente contratado pela tomadora. Essa discrepância decorre da inclusão do lucro pelo gerenciamento da mão de obra no valor repassado à prestadora de 
serviços. A reduzida estabilidade do trabalhador terceirizado apresenta-se igualmente como fator prejudicial, vez que o funcionamento da prestadora e a manutenção dos contratos dos empregados dependem da variável necessidade da tomadora.

\section{PRECARIZAÇÃO NO TRABALHO}

Em tempos de globalização e de crise econômica estrutural, acirram-se os desafios de preservação dos direitos sociais, como o direito ao trabalho. A geração de renda quase exclusivamente sujeita aos níveis de produção e consumo redunda em danos sociais, tais como a maior rotatividade no emprego, a diminuição da renda dos trabalhadores, o agravamento das consequências à saúde obreira, além de outros malefícios decorrentes do deslocamento territorial das empresas à procura de mercados mais atrativos.

Nesse sentido, Gadotti (2000, p. 136) identifica a globalização do modo de produção capitalista como um "modelo de dominação econômico, político e cultural totalitário e excludente" e também reconhece que o processo de globalização da sociedade civil "possibilita novos movimentos sociais, políticos e culturais, intensificando a troca de experiências de suas particulares maneiras de ser, questionando as desigualdades no interior dos Estados-nações". A globalização faz cada um de nós cúmplices e culpados pelo que ocorre com as outras pessoas sobre a Terra (SANTOS, 2015, p. 252), na tentativa de superação das desigualdades e de "fortalecimento da perspectiva democrática no seio da própria sociedade civil” (GADOTTI, 2000, p. 136).

A Terceira Revolução Industrial provocou mudanças profundas no mundo do trabalho. Desencadeou a descentralização do capital e o desemprego tecnológico. Grandes empresas, antes verticalmente estruturadas, adotaram o modelo horizontalizado, em nome da diminuição dos custos e do aumento da produtividade. Setores produtivos foram terceirizados e formou-se uma espécie de rede, juntamente com outros empreendimentos. Parte das atividades antes desempenhadas por empregados diretos passa a ser exercida por trabalhadores estranhos ao estabelecimento beneficiário, sem o patamar de garantias e direitos trabalhistas de outrora.

Essa configuração dos postos de trabalho prejudica as garantias sociais e trabalhistas conquistadas ao longo da história. Se antes a empresa contratava o empregado, hoje contrata a prestação de serviços. Com a nova estratégia empresarial, diminui-se o custo do trabalho, porquanto se afasta a necessidade de pagamento do período de ociosidade ou de baixa na demanda. As tomadoras experimentam o aumento da produtividade e da competitividade, vantagens que explicam a falta de interesse em modificar o quadro de exploração.

Deflagra-se um processo de esvaziamento da luta de classes. Os trabalhadores perdem a identidade coletiva, por motivo da intensificação da heterogeneidade e da fragmentação no mundo do trabalho. A globalização, o neoliberalismo e as organizações produtivas flexíveis facilitam o descarte em massa de trabalhadores e a ampliação do nível de pobreza.

Sobre o tema, Teitelbaum (2000, p. 27) afirma que "el empresario ya no ve al trabajador como un factor de producción y también como un consumidor (fordismo), sino sólo como un factor de producción cuyo costo hay que reducir en aras de la competitividad internacional". E frisa, ainda, que a ameaça de perder o emprego e a extensão dos empregos precários contribuem para diminuir a qualidade da vida ativa, independentemente da qualificação do 
trabalho, citando como exemplos a "irregularidad y extensión en los hechos del horario de trabajo, incremento de la insalubridad y la inseguridad laboral, aumento de los accidentes de trabajo, de las enfermedades profesionales y del stress" (TEITELBAUM, 2000, p. 29).

Logo, devem ser profundamente discutidos os rumos que determinadas medidas legislativas podem tomar, tendo em vista os possíveis reflexos nos contextos local e mundial. É o caso da terceirização e as consequências que podem advir da autorização para estendê-la às atividades finalísticas.

\section{TERCEIRIZAÇÃO E FRAGILIZAÇÃO DOS DIREITOS TRABALHISTAS}

Define-se terceirização como o fenômeno pelo qual se dissocia a relação econômica da relação justrabalhista correspondente (DELGADO, 2012). O trabalhador integra o processo produtivo da tomadora sem que se beneficie com o laço justrabalhista, que o mantém vinculado à prestadora interveniente. Portanto, a terceirização compreende uma relação trilateral. O trabalhador realiza suas atividades em favor da tomadora de serviços. A tomadora recebe a prestação de labor, mas não assume a posição clássica de empregadora, mantendo tão somente uma relação de viés econômico com a prestadora. Enfim, a prestadora é que funciona como empregadora, conquanto o labor beneficie diretamente a tomadora.

Embora conserve características comuns, a terceirização apresenta particularidades a depender do país. No Brasil, emprega-se o termo terceirização, que não se identifica com a tradução literal de outsourcing, utilizada em países de língua inglesa, que significa fornecimento vindo de fora. Em vernáculo, a prática de terceirizar transmite a ideia de trabalho realizado por terceiros, algo feito por outras pessoas.

Com origem fundamentada em justificativas econômicas almejadas pela globalização focalização da produção para elevar a produtividade e a qualidade como diferenciais para a competitividade e a redução dos custos totais de produção -, no país, a terceirização tem sido utilizada primordialmente para reduzir custos e afastar obrigações trabalhistas da tomadora, gerando inúmeras consequências no tocante ao meio laboral.

O gradual encolhimento dos direitos trabalhistas na terceirização pode ser constatado a partir da observação de dados estatísticos que denunciam, por exemplo, o menor tempo de permanência nos empregos, a média salarial reduzida, o enfraquecimento das categorias com a desagregação dos sindicatos e a maior incidência de eventos adversos - acidentes do trabalho e doenças ocupacionais (DIEESE, 2010).

Os elevados índices de acidentes de trabalho nas atividades terceirizadas denunciam os riscos da terceirização interna de serviços e a maior precariedade das condições ambientais laborais nesse âmbito, fator atribuível "à pressão exercida pela lógica de mercado à redução do custo de produção, com o consequente rebaixamento do investimento, inclusive em medidas de saúde e segurança dos trabalhadores" (DELGADO; AMORIM, 2014, p. 110).

Desvirtua-se a finalidade original de focalização, defendida pelo toyotismo, para se intensificar o processo de coisificação da pessoa trabalhadora. Aproxima-se da 
comercialização do trabalho, comportamento banido pelo Anexo à Declaração de Filadélfia, de 1944, que aborda os objetivos e fins da OIT e reconhece o valor social do trabalho e da dignidade humana, ao preconizar que o trabalho não é uma mercadoria.

Precisa-se combater a subordinação dos trabalhadores à lógica da flexibilidade. Para Antunes e Druck (2014, p. 17), o capital reafirma a força de trabalho como mercadoria, estabelecendo que "o descarte e a superfluidade são fatores determinantes para um grau de instabilidade e insegurança no trabalho, como nunca antes alcançado". Revelam, ainda, que a centralidade da terceirização na estratégia patronal concretiza formas de compra e venda da força de trabalho. Essa prática disfarça ou traveste as relações sociais entre capital e trabalho como se envolvessem empresas ou instituições, não obstante tenham por base contratações de pessoal por tempo determinado, flexíveis, em função do ritmo produtivo das tomadoras e das oscilações de mercado que desestruturam o trabalho.

Esconde-se o ponto fundamental, concernente no fato de a terceirização ter como objetivos centrais a redução dos salários, a constante retração dos direitos do trabalho e o aumento da fragmentação, para desorganizar a classe trabalhadora na esfera sindical e nas distintas formas de solidariedade coletiva. Salários menores, jornadas mais extensas e altas taxas de rotatividade revelam que a terceirização domina o processo de corrosão do trabalho, razão pela qual está no centro dos debates mundo afora (ANTUNES E DRUCK, 2014, p. 24).

Porta de entrada para a degradação estrutural do trabalho, a terceirização insere-se no conjunto de pleitos do capital pela redução de salários, pelo desmonte da legislação social protetora do labor e pela reforma redutora e privatizante da previdência. Esse conjunto de medidas representa prejuízos aos direitos sociais arduamente conquistados pela classe trabalhadora ao longo de séculos (ANTUNES, 2014, p. 30).

A terceirização disseminou-se e pode espalhar-se de modo mais contundente. O direito do trabalho tradicional passou a ser considerado um privilégio. Em vez de permitir a concentração do tomador na sua atividade principal e a melhoria de qualidade dos produtos e serviços, o desvirtuamento do instituto gera precarização do trabalho humano, pois serve de instrumento unicamente voltado à redução de direitos trabalhistas. A fórmula de redução de gastos impele que se considere no cálculo o lucro e os custos da prestadora de serviços. Assim, os prejuízos são repassados ao trabalhador, na forma de submissão a precárias condições laborais e da falta de atendimento à integralidade dos direitos (SOUZA, 2009).

\section{FALTA DE HIGIDEZ DO MEIO AMBIENTE LABORAL NA TERCEIRIZAÇÃ̃O}

O trabalho não pode ser visualizado como uma simples mercadoria de troca pela sobrevivência ou subsistência, pois consagra valores que dignificam o ser humano no contexto social, psicológico e cultural. Na medida em que as organizações geram externalidades negativas (degradação ambiental e prejuízos sociais) e externalidades positivas (desenvolvimento e geração de riquezas), devem assumir o papel principal em ações voltadas à garantia de um futuro sustentável. Segundo o tripé do desenvolvimento sustentável, uma sociedade somente pode ser considerada sustentável se atender aos critérios de relevância social, da prudência ecológica e da viabilidade econômica (CIRINO, 2014). 
Conforme Araújo Júnior (2014), para corresponderem ao binômio da maximização dos lucros e redução dos custos, as condições dos trabalhadores são fragilizadas, gerando mais acidentes laborais entre os terceirizados. $\mathrm{O}$ ambiente degradado decorre da falta de cuidado com as questões de segurança, pela exposição dos profissionais a ambientes inadequados. Esse comportamento deve ser repelido. Antes de objetivar a acumulação de capital, o empreendimento vincula-se à ordem econômica estruturada pela Constituição, que estabelece como fundamentos a dignidade humana (art. $1^{\circ}$, III), o valor social do trabalho (art. $1^{\circ}$, IV) e a função social da propriedade (art. 170, III), demandando a ação empresarial responsável como instrumento de proteção ao meio ambiente do trabalho.

No caso do trabalho terceirizado e a efeito de exemplo, destacam-se dois setores entre os que mais geram acidentes, doenças e mortes relacionados ao desempenho da atividade laboral: elétrico e construção civil.

Quanto à precarização no setor elétrico, pesquisas do Departamento Intersindical de Estatística e Estudos Socioeconômicos (DIEESE) apontam que os acidentes fatais se concentram nos trabalhadores terceirizados (SILVA JÚNIOR, 2014). Em 2007, dos acidentes fatais registrados para o setor, $83,09 \%$ vitimaram terceirizados. No ano de 2008 , os terceirizados representaram $80 \%$ dos prejudicados.

Por outro lado, Filgueiras (2015) afirma que a construção civil é o setor que mais mata trabalhadores no Brasil, registrando oficialmente mais de 450 fatalidades a cada ano. Os dados dos Anuários Estatísticos de Acidentes de Trabalho (AEAT) de 2013 apontam que, dos 2.797 acidentes fatais ocorridos no Brasil, 451 foram na construção. O autor alerta que, de acordo com os AEAT de 2006 a 2012, o total de óbitos no setor cresceu 58,4\%, sem considerar a subnotificação.

Quando contratam trabalhadores por meio da terceirização, as tomadoras têm mais facilidade para impor medidas que incrementam a acidentalidade (FILGUEIRAS, 2015). Ao lado da externalização produtiva, existe o repasse dos riscos ocupacionais, resultando em maior acidentalidade entre os terceirizados. $\mathrm{O}$ agravamento do quadro decorre da análise de dados estatísticos, que revelam um salto na quantidade de mão de obra terceirizada. O sindicato que representa os trabalhadores terceirizados no estado de São Paulo (Sindeepress) informa que, de 1995 a 2010, a quantidade de vínculos aumentou cerca de sete vezes, atingindo a marca de $700 \mathrm{mil}$, e a de empresas quase quintuplicou, totalizando aproximadamente 5,4 mil (CARTA CAPITAL, 2011).

São questões que envolvem o meio ambiente laboral, o qual deve ser preservado e defendido, tal como orientam os princípios da prevenção e da precaução, com respaldo no conjunto de normas internacionais e internas a respeito do tema.

A Declaração Universal dos Direitos Humanos, de 1948, a Declaração de Estocolmo, de 1972, e a Declaração do Rio, de 1992, são os três principais documentos internacionais relacionados ao meio ambiente. No âmbito interno, a Constituição reconhece o direito ao meio ambiente ecologicamente equilibrado, essencial à sadia qualidade de vida, nele compreendido o do trabalho (art. 200, VIII, e o art. 225, caput, da CR/88). O cuidado com o meio ambiente, a função social da propriedade e a busca do pleno emprego são princípios da ordem econômica, a qual se funda na valorização do trabalho humano e na livre iniciativa, com o fim de assegurar a todos uma existência digna, conforme os ditames da justiça social 
(art. 170). Enfim, além de outros que visem à melhoria da sua condição social (art. $7^{\circ}$, caput), são direitos fundamentais a redução dos riscos inerentes ao trabalho, por meio de normas de saúde e segurança (art. $7^{\circ}$, XXII), e o seguro contra acidentes de trabalho, a cargo do empregador, sem excluir a indenização quando houver dolo ou culpa (art. $7^{\circ}, \mathrm{XXVIII).}$

\section{PLC 30/2015 (PL 4.330/2004) E A Terceirização Na Atividade-Fim}

O conteúdo do PLC 30/2015 - numeração assumida pelo PL 4.330/2004, agora em trâmite no Senado Federal - estimula a precarização, atenta contra a vida dos trabalhadores, estabelece a desigualdade e a discriminação, afasta direitos e legaliza as iniciativas patronais reiteradamente condenadas pela Justiça do Trabalho (DRUCK; SILVA, 2014, p. 39). Não combate a intermediação de mão de obra. Pelo contrário, incentiva-a ao liberar a rede de subcontratação sucessiva e ilimitada.

A regulamentação da terceirização no Brasil deve ter por objetivo afastar o quadro de precarização existente e ir além do panorama jurisprudencial traçado até o momento pela Súmula 331 do TST. O modelo de generalização das hipóteses de admissibilidade não estimula a empregabilidade. Na verdade, provoca a substituição dos empregos diretos, de melhor qualidade, por terceirizados, geralmente menos protegidos. Como ressalta Caixeta (2013, p. 815), o princípio da vedação à mercantilização do trabalho impede que a terceirização se estenda além das atividades especializadas, acessórias e secundárias, devendo-se preservar a regra da contratação direta para os serviços ligados à atividade nuclear da empresa. Ou seja, a terceirização deve ser tratada como exceção, aceita apenas nas atividades-meio e vedada nas atividades-fim.

Quanto à noção de atividade-fim, trata-se de produto da atualização do conceito de relação de emprego e considera as alterações sentidas nos elementos caracterizadores da subordinação, tomando-se por base a Lei 5.645/70 e o Decreto Federal 2.271/1997. Contratar diretamente o trabalho ligado ao núcleo do empreendimento representa vantagens para a administração pública. A coleta de impostos, a manutenção do sistema solidário previdenciário e a tutela preventiva da saúde do trabalhador repercutem sobremaneira no sistema de saúde pública. Ademais, a continuidade da relação de emprego, a limitação da jornada e o pagamento da remuneração adequada compõem a economia nacional e propiciam a atividade consumerista do indivíduo empregado. Logo, a limitação da terceirização à atividade-meio mostra-se como medida indispensável ao bom funcionamento da ordem econômica e dos direitos trabalhistas mais básicos (MELO; ARAUJO, 2015, p. 287).

Como Delgado e Amorim (2014, p. 105) alertam, a pretensão de terceirizar a atividade finalística do empreendimento frustra os "elementos nodais do regime de emprego, fomentando a marginalização econômica e social do trabalhador, em violação ao seu direito fundamental à relação de emprego maximamente protegida" e, com isso, atinge-se o princípio central da constituição econômica e os ideais do trabalho decente orientadores da integração brasileira à política internacional de promoção dos direitos humanos. 
A terceirização da atividade-fim do empreendimento esvazia os limites constitucionais da função social da livre iniciativa, da propriedade, do contrato e do trabalho, que pregam o desenvolvimento pautado na proteção dos direitos laborais. A Constituição confere proteção específica ao trabalhador (art. $7^{\circ}$ a 11 ), destaca a função social do trabalho como fundamento da República (art. $1^{\circ}$, IV) e como parâmetro basilar da ordem econômica (art. 170) e social (art. 193), além de garantir o viés expansionista da proteção social, ao possibilitar a instituição de outros direitos e garantias que visem à melhoria da condição social (art. $7^{\circ}$, caput) e, portanto, somem-se aos previstos originalmente no texto.

$\mathrm{O}$ art. 23 da Declaração Universal de Direitos Humanos ${ }^{2}$ consagra o direito ao trabalho e tutela da qualidade do emprego, que deve ser realizado em condições justas e favoráveis. $\mathrm{O}$ art. $7^{\circ}$ do Pacto Internacional de Direitos Sociais, Econômicos e Culturais ${ }^{3}$ segue o mesmo caminho de outras normas infraconstitucionais - especialmente da OIT -, que defendem a superação do desemprego, eliminação do trabalho precário e a promoção do trabalho decente, em prol dos direitos fundamentais e da dignidade humana (SANTOS, 2015, p. 245).

Vista em conjunto com outros instrumentos internacionais $\left(\operatorname{art} .5, \S 2^{\circ}\right)^{4}$, a Constituição deve ser visualizada como um patamar mínimo de direitos, passível de ampliação para viabilizar o alcance da dignidade pelo trabalho, pois atua como fator condicionante do gozo de outros direitos, como o acesso à rede de proteção social.

Em matéria de terceirização, impõe-se ao legislador infraconstitucional que se restrinja a editar normas especiais protetivas do trabalhador terceirizado na atividade-meio da tomadora de serviços, "a fim de aproximar ao máximo esse regime de emprego do padrão constitucional de proteção social, visando à máxima superação do regime de emprego rarefeito, próprio da terceirização" (DELGADO; AMORIM, 2014, p. 142).

O quadro de precarização pode ser agravado, em caso de aprovação do PLC 30/2015 no Senado Federal. De acordo com o projeto, a terceirização passa a admitir que uma empresa

\footnotetext{
2 Art. 23. I) Toda a pessoa tem direito ao trabalho, à livre escolha do trabalho, a condições equitativas e satisfatórias de trabalho e à proteção contra o desemprego. II) Todos têm direito, sem discriminação alguma, a salário igual por trabalho igual. III) Quem trabalha tem direito a uma remuneração equitativa e satisfatória, que lhe permita e à sua família uma existência conforme com a dignidade humana, e completada, se possível, por todos os outros meios de proteção social. IV) Toda a pessoa tem o direito de fundar com outras pessoas sindicatos e de se filiar em sindicatos para defesa dos seus interesses.
}

${ }^{3}$ Art. $7^{\circ}$. Os Estados Partes do presente Pacto reconhecem o direito de toda pessoa de gozar de condições de trabalho justas e favoráveis, que assegurem especialmente:

a) Uma remuneração que proporcione, no mínimo, a todos os trabalhadores: i) Um salário eqüitativo e uma remuneração igual por um trabalho de igual valor, sem qualquer distinção; em particular, as mulheres deverão ter a garantia de condições de trabalho não inferiores às dos homens e perceber a mesma remuneração que eles por trabalho igual; ii) Uma existência decente para eles e suas famílias, em conformidade com as disposições do presente Pacto;

b) A segurança e a higiene no trabalho;

c) Igual oportunidade para todos de serem promovidos, em seu Trabalho, à categoria superior que lhes corresponda, sem outras considerações que as de tempo de trabalho e capacidade;

d) O descanso, o lazer, a limitação razoável das horas de trabalho e férias periódicas remuneradas, assim como a remuneração dos feridos.

${ }^{4}$ Art. $5^{\circ}[\ldots] \S 2^{\circ}$. Os direitos e garantias expressos nesta Constituição não excluem outros decorrentes do regime e dos princípios por ela adotados, ou dos tratados internacionais em que a República Federativa do Brasil seja parte. 
abandone uma ou mais atividades realizadas por trabalhadores contratados diretamente e as transfira para outra, independentemente da natureza finalística ou acessória do serviço (SANTOS; BORGES, 2015, p. 263).

A eliminação da diferença de tratamento entre as atividades nucleares e as acessórias, com permissão para subcontratar todos os serviços, significará o aumento do contingente de trabalhadores terceirizados, em relação aos diretamente contratados.

Atualmente, apenas as atividades secundárias podem ser delegadas. O TST, ao interpretar o panorama legislativo, indica como serviços passíveis de terceirização os de limpeza, conservação e vigilância, e os específicos, desde que diversos do núcleo do empreendimento (Súmula 3315).

Entre os principais problemas que podem decorrer dessa abertura legislativa, Locatelli (2015) destaca os seguintes: achatamento salarial; diminuição do número de empregos diretos; elevação dos riscos de acidente; aumento do preconceito; prejuízo à negociação coletiva; expansão do trabalho escravo; impunidade dos maus empregadores; mais facilidade para corrupção; diminuição na arrecadação e aumento dos gastos públicos.

O processo legislativo não deve instrumentalizar a redução do patamar protetivo vigente, nem servir para legitimar práticas indignas de subemprego, informalidade, discriminação, excesso de jornada, assédio, remuneração reduzida, além de outras ofensas aos trabalhadores terceirizados. Pelo contrário, há que se buscar a maior proteção do empregado, por ser a parte mais frágil da relação.

A legislação precisa representar mais proteção aos direitos trabalhistas na terceirização e superar as estatísticas negativas, notadamente no que tange à higidez do meio ambiente laboral e às condições de trabalho inadequadas.

Diante dos danos relacionados à terceirização tal como atualmente aceita - atividades acessórias e especializadas -, sobram motivos para rejeição das tentativas de ampliação das possibilidades existentes, vez que o princípio do não retrocesso em matéria de direitos sociais (art. $7^{\circ}$, caput, da $\mathrm{CR} / 88$ ) e a função social da empresa e do trabalho repelem a mercantilização do trabalho e a prática de terceirização da atividade finalística.

\section{CONCLUSÃO}

O desenvolvimento de novas técnicas e modelos produtivos corresponde a uma necessidade do sistema capitalista. As alterações devem considerar, além dos interesses dos detentores dos meios de produção, os direitos fundamentais das pessoas trabalhadoras, que vendem a força laboral em busca de uma vida digna e da realização pelo trabalho.

\footnotetext{
${ }^{5}$ Súmula 331. [...] I - A contratação de trabalhadores por empresa interposta é ilegal, formando-se o vínculo diretamente com o tomador dos serviços, salvo no caso de trabalho temporário (Lei n ${ }^{\circ}$ 6.019, de 03.01.1974). [...] III - Não forma vínculo de emprego com o tomador a contratação de serviços de vigilância (Lei $\mathrm{n}^{\circ} 7.102$, de 20.06.1983) e de conservação e limpeza, bem como a de serviços especializados ligados à atividade-meio do tomador, desde que inexistente a pessoalidade e a subordinação direta. [...]
} 
A gravidade e a extensão dos efeitos de eventual regulamentação equivocada do instituto da terceirização revelam que essa decisão não prescinde da consideração de estudos prévios sobre os impactos da medida, em respeito aos anseios democráticos e sociais. $\mathrm{O}$ regramento precisa ter como norte a ampliação da proteção existente, não o agravamento do quadro de descaso e precarização a que submetidos os trabalhadores terceirizados.

Índices de acidentes e mortes relacionadas ao trabalho terceirizado clamam por um regramento compatível com o dever de cuidado exigível de todos os beneficiários da prestação de trabalho alheio. Os possíveis retrocessos provenientes de eventual aprovação do PLC 30/2015 devem servir de alerta para o impedimento da ampliação das possibilidades de terceirização para além dos parâmetros atualmente estabelecidos.

O princípio da não mercantilização do trabalho e o caráter fundamental do conjunto de normas constitucionais relativas a esse importante direito social exigem o exercício do direito à livre iniciativa, o qual deve se manter atento à função social.

A subcontratação de atividades nucleares do empreendimento ameaça todo o sistema protetivo traçado pelo Constituinte. O respeito ao mínimo de regramento contido na Súmula 331 do TST e a visão mais ampliada da garantia de direitos aos trabalhadores terceirizados corresponde à decisão mais acertada para esse momento inicial de regulamentação da prática.

Como visto, o ordenamento jurídico oferece instrumentos jurídicos suficientes para a defesa do regime de trabalho e da vinculação direta entre o beneficiário e o prestador dos serviços, especialmente quando essas atividades forem centrais para a consecução do objeto do empreendimento, no exercício social da livre iniciativa e em respeito à importância do trabalho para o gozo dos direitos fundamentais reconhecidos pelo texto constitucional e pelas normas internacionais integrantes do ordenamento pátrio. 


\section{REFERÊNCIAS}

ANTUNES, Ricardo. A corrosão do trabalho e a precarização estrutural. in DELGADO, Gabriela Neves; PEREIRA, Ricardo José Macêdo de Britto Pereira (org.). Trabalho, constituição e cidadania: a dimensão coletiva dos direitos sociais trabalhistas. São Paulo: LTr, p. 27-30, 2014.

DRUCK, Graça. A epidemia da terceirização. in ANTUNES (org.). Riqueza e miséria do trabalho no Brasil III. 1. ed. São Paulo: Boitempo, p. 13-24, 2014.

ARAÚJO JÚNIOR, Francisco Milton. A terceirização e o descompasso com a higidez, saúde e segurança no meio ambiente laboral - responsabilidade solidária do tomador do serviço a partir das normas de saúde e segurança no trabalho. in Revista do Tribunal Regional do Trabalho da $3^{a}$ Região. Belo Horizonte, v. 58, n. 89, p. 67-81, 2014.

BRASIL. Constituição (1988). Constituição da República Federativa do Brasil. Brasília: Senado, 1988. Disponível em: 〈www.planalto.gov.br/ccivil_03/constituicao/constituicao.htm>. Acesso em: 10 jun. 2016.

Decreto 591, de 6 de julho de 1992. Promulgação do Pacto Internacional sobre Direitos

Econômicos, Sociais $\quad$ e $\quad$ Culturais. $\quad$ Disponível em

<http://www.planalto.gov.br/ccivil_03/decreto/1990-1994/d0591.htm>. Acesso em: 13 jun. 2016

CAIXETA. Sebastião Vieira. Apontamentos sobre a normatização do instituto da terceirização no Brasil: por uma legislação que evite a barbárie e o aniquilamento do direito do trabalho. in MIESSA, Élisson; CORREIA, Henrique. Estudos aprofundados - Ministério Público do Trabalho. 2. ed. Salvador: JusPodivm, p. 801-817, 2013.

CIRINO, Samia Moda. Sustentabilidade no meio ambiente de trabalho: um novo paradigma para a valorização do trabalho humano in Revista Eletrônica Direito e Sustentabilidade. Tribunal Regional do Trabalho da $9^{a}$ Região, v. 3, n. 28, p. 85-108, 2014.

DELGADO, Gabriela Neves; AMORIM, Helder Santos. Os limites constitucionais da terceirização. 1. ed. São Paulo: LTr, 2014.

DELGADO, Maurício Godinho. Curso de direito do trabalho. 11 ed. São Paulo: Ltr, 2012. 
DIEESE. Terceirização e morte no trabalho: um olhar sobre o setor elétrico brasileiro. São Paulo: DIEESE, 2010.

DRUCK, Graça; SILVA, Jair Batista da. Precarização, terceirização e ação sindical. in DELGADO, Gabriela Neves; PEREIRA, Ricardo José Macêdo de Britto Pereira (org.). Trabalho, constituição e cidadania: a dimensão coletiva dos direitos sociais trabalhistas. São Paulo: LTr, p. 31-45, 2014.

FILGUEIRAS, Vitor Araújo. Terceirização e acidentes de trabalho na construção civil in FILGUEIRAS, Vitor Araújo et al (org.). Saúde e segurança do trabalho na construção civil brasileira. Aracaju: J. Andrade, p. 61-86, 2015.

GADOTTI, Moacir. Pedagogia da terra. 2. ed. São Paulo: Peirópolis, 2000.

LOCATELLI, Piero. Nove motivos para você se preocupar com a nova lei da terceirização. Carta Capital, 2015.2 Disponível em: <http://www.cartacapital.com.br/politica/novemotivosparavocesepreocuparcomanovaleidaterceirizaca o2769.html>. Acesso em: 04 jun. 2016.

MELO, Luis Antonio Camargo de; ARAUJO, Adriane Reis de. Terceirização da atividade-fim na jurisprudência do TST. in MIESSA, Élisson; CORREIA, Henrique. Estudos aprofundados Ministério Público do Trabalho. v. 2. Salvador: JusPodivm, p. 275-287, 2015.

ORGANIZAÇÃO DAS NAÇÕES UNIDAS. Declaração do rio sobre meio ambiente e desenvolvimento. Disponível em: <http://www.onu.org.br/rio20/img/2012/01/rio92.pdf>. Acesso em: 12 jun. 2016.

ORGANIZAÇÃO INTERNACIONAL DO TRABALHO. Conferência Internacional do Trabalho. Declaração relativa aos fins e objetivos da organização internacional do trabalho. Disponível em <http://www.dgert.msess.pt/declaracao-de-filadelfia>. Acesso em: 13 jun. 2016.

SANTOS, Leyde Aparecida Rodrigues dos; BORGES, Amanda Tavares. Projeto de lei 4330/04 novos rumos da terceirização no Brasil. in NASCIMENTO, Grasiele Augusta Ferreira; SILVA, Luciana Aboim Machado Gonçalves da; CECATO, Maria Aurea Baroni (coord). Direito do trabalho e meio ambiente do trabalho II [Recurso eletrônico on-line] CONPEDI/UFMG/FUMEC/Dom Helder Câmara (org.). Florianópolis: CONPEDI, p. 244-269, 2015.

SILVA JÚNIOR, Antônio Braga da. A terceirização e o supremo (parte 6): a terceirização do risco no ambiente de trabalho. 30 jun. 2014. Disponível em: 
<http://trabalhoconstituicaocidadania.blogspot.com.br/2014/07/aterceirizacaodorisconoambientede.ht $\mathrm{ml}>$. Acesso em: 30 mai. 2016.

SOUZA, Marcius Cruz da Ponte. Neoliberalismo e globalização: reflexos no direito do trabalho. Revista Jus Navigandi, Teresina, ano 14, n. 2231, 10 ago. 2009. Disponível em: <https://jus.com.br/artigos/13300>. Acesso em: 11 jun. 2016.

TEITELBAUM, Alejandro. La crisis actual del derecho al desarrollo. in Cuadernos Deusto de Derechos Humanos. n. 11. Bibao: Universidad de Deusto, 2000. 